\title{
Engaging in Development and Evaluation of Experiential Learning: Games and Simulations
}

\author{
Alina M. Zapalska \\ U.S. Coast Guard Academy, USA
}

\begin{abstract}
The use of games and simulations in the classroom has prompted research concerning their pervasiveness and pedagogical benefits, but little research has focused on how teachers can develop and evaluate effectiveness of their own games and simulations. This paper presents an outline of how to develop and evaluate those experiential learning techniques for classroom use.
\end{abstract}

Keywords: Experiential Learning, Active Learning, Games, Simulations, Assessment, Effectiveness of Learning

\section{Introduction}

The use of games and simulations as a teaching strategy is receiving serious attention, and many college teachers have embraced them with great enthusiasm [1]. Simulations and games require students' active participation and decision making throughout the learning process. They also allow practicing real life behaviors in simulated scenarios and eliciting students' responses to situations that illustrate realistic environments [2]. In a simulated environment, failure can be a learning event without real-world consequences.

Litvin and Elangovan argue that some research has been developed into designing games and simulations, but the use of those instruments is not well understood because faculty experience with them is quite limited [3]. According to Brozik and Zapalska, some possible explanations for such limited use are the lack of objective information about those experiential learning techniques, lack of faculty exposure to those techniques, lack of knowledge concerning appropriate active instruments, difficulty in previewing those instruments without actually playing them, and difficulty in evaluating those experiential learning techniques [4].

Designing effective and interesting experiential learning instruments for use in the classroom requires a great deal of work on the part of the teacher. Designing of those instruments is not inherently difficult but there are many questions associated with designing and using games and simulations, such as the role of the instructor, the time and space required, evaluation procedures, and the benefits and drawbacks of using them [5], and there is little research about how teachers can develop their own experiential learning activities. This paper presents an outline to aid in the development of games and simulations and presents the example of developing the "Market Game" followed by a short discussion on the evaluation of students learning in this experiential environment.

\section{Literature review}

Supporters of Kolb's experiential learning cycle recommend application of various methods of learning that range from concrete, abstract, active, passive, primary, and secondary modes of learning especially active learning through service learning, internships, field trips, and involvement in faculty research [6][7]. Requiring students to be active learners through experiential activities and practice promotes the effectiveness of learning [8][9]. An example of learning from experience can be demonstrated with the use of experiential learning with simulations and games where active learning is based on reflective practice that places students in situations where they must perform tasks in order to gain new experiences and skills [10].

Cohen [11] contend that learning will be effective if students are involved in a deep learning process where students learn from experience. The author supported the experiential learning cycle because it advances social skills, work ethic, practical expertise, and critical thinking. Application of knowledge through active and experiential learning using complex and uncertain situations will allow students to develop critical thinking and the ability to engage in lifelong learning. Some researchers recommended involving students in deep learning through active and cooperative learning and experimentation [12]. Brozik and Zapalska also endorsed games and simulations for experiential learning [13].

Simulations and games have been used in business and economics courses throughout the country [14] and have been shown to provide students with an effective means of learning through experiences taken from actual situations and presented in a controlled environment [15]. A variety of simulations and games ranging from simple to complex can be found for many classes in 
today's business and economics college curricula [16].

DeYoung [17] states that group learning using games and simulations begins with concrete experiences. Relying on reflective observations from those experiences, students engage in abstract conceptualization that allows them to generalize and learn principles that integrate their observations into working theories. Games and simulations enable students to experiment, test, and apply what they have learned in and to other, more complex, situations. Hoggat [18] and Koster [19] argue that activity eliminates memorization and repetition and gives students opportunities to interact with each other. Zapalska and Brozik [20] argue that experiential techniques prompt students to solve problems and stimulate strategic, reflective, and critical thinking. Other papers on the effects of learning with games and simulations suggest improvement on interpersonal measures, positive effects on academic achievement measures, and improved attitudes toward school [21][22]. Several authors have recognized that those experiential instruments enable more positive student relationships, increase individual motivation, and promote a healthier psychological environment than any other classroom method [23][24][25][26].

Games that seek to demonstrate a fundamental concept may be very simple in structure [27][28]. In some cases, multiple repetitions of a simple game may be conducted in order to illustrate the principle. Other games that seek to model complex operations may have many aspects that must be mastered [29]. Games like this can take weeks to complete. While both short and long games have their uses, many instructors find it desirable to have a game that takes a single class period and illustrates a specific concept or can be used to identify and develop specific behavioral characteristics. Single period simulations and games also have the advantage of being flexible in their application; instructors can change plans according to the needs of the class and move the game to a different time without causing major disruptions in the class schedule [30].

\section{Defining games and simulations}

A game can be defined as an interaction that involves a winner. A game features competitive interaction to achieve pre-specified goals and those interactions may feature cooperation within groups, but competition either among individuals or groups is a distinguishing characteristic of games. The winner of the game is the individual or team that learns enough about the structure and content of the game to achieve the goal and win the game. A game may be played for entertainment, but it will still have clearly identified winners and losers. Participants' success is dependent upon skill or chance or some combination of the two. A game makes no attempt to replicate real world behavior. Rules of behavior for the game need apply to the game only.

Simulations model a portion of reality in a controlled setting and reproduce the social, economic, or political processes of particular systems of social interactions. Students assume roles in the system and try to understand how the system operates by participating as members, not merely as observers. A simulation is a controlled environment created for the purpose of learning that allows the learners to take risks and gives them direct access to the subject matter. The learner can become empowered to make decisions, test theories and hypothesis and make mistakes without suffering real consequences. Reality is replicated to the degree that the simulation designer selects essential elements from reality being modeled.

A carefully designed game or simulation capitalizes on the motivation of the learner, the social nature of learning, and the experiential nature of learning. Learner's experience, reflect, and conceptualize learning with outcomes that can transfer to real situations. The learner is motivated through social interaction and can develop independent as well as interdependent behaviors. Within the simulation or the game, independence is fostered through guidance as the learner is faced with greater autonomy relative to the learner's experience with the content. Interdependence is fostered through the intentional role interaction of the participants as well as through dialogue reflection built into simulation. Through reflection the learners form abstract concepts and generalizations to be tested within the simulation. The learners form concepts based on experienced and receive intrinsic feedback. Games and simulations are different, but though the final results may differ as there are many factors that are common to both. The following discussion will use the terms "game" and "simulation" interchangeably or in conjunction.

\section{Developing games and simulations}

The steps given below are intended to help identify those design parameters that are necessary to create a meaningful experiential exercise.

\subsection{Identify the problem and the structure of the game}

First stage of the game or simulation development involves selecting a problem. What are the concepts we want our students to understand? What problems do we want our students to solve in order to understand those concepts? We also should consider where our personal interests coincide with our answers to those questions. This inquiry will lead to some preliminary ideas for concepts that we want 
to demonstrate in our game or simulation. It is important that we examine our personal attitudes with respect to the problem. There is no way we will be able to construct a meaningful simulation that does not resonate with our personal experiences and beliefs.

\subsection{Define the learning objective and scope}

It is critical that we clearly define the learning objectives and scope of the exercise. We must be sure to write them down. We should revisit and refine our statement of learning objectives and scope after completing each of the following steps. The continuing redefinition of the objectives and scope is critical since it is impossible to model all issues and policies simultaneously. Each step in the development of a simulation brings new questions about what we really want to do. Large problems can become small, but it is more likely that small problems will become large. We must deal with each "expansion" of the question to determine whether or not it will lead us to our intended goal. At this point, we should have already decided whether we are building a simple or complex exercise. It is necessary to stop and review each step of the development process to assure that we are staying to our original plan.

\subsection{Define the players organizations, and environment}

Any game or simulation involves business and social processes in which key decisions and movement are provided by players operating either as individuals or in groups or as ad hoc organizations. Players are identified by their "roles" which can be jobs such as salesperson, trader, president of business, or manager. Within organizations players can also be identified by their roles as consumers, traders, and policy makers. It is necessary to designate the key organizations involved and then identify the key players within those organizations. If we cannot specify "who" will be playing the game, we will not be able to move on to the next step in simulation design.

\subsection{Define the motives, incentives, and goals of the players}

Each organization, role, business, or culture offers its actors certain approved goals, certain resources, and action options which they can use to achieve their goals as well as specific constraints on their behavioral choices. A social or business environment in a simulation or a game can be achieved by defining the goals of the players and the rules concerning what they can and cannot do with their available resources (see next step) within the defined constraints. It is critical to define the motives and goals of the players as specifically as possible (i.e., define their objective function) which will enable players to get a fast start, and we as the game designer will be free to focus on the key areas of conflict-cooperation in the game. If the simulation is to move along smartly, it must have a clean "starting line". Many areas of conflict will emerge if the objectives of the actors are not clearly defined. This situation creates a waste of critical time, particularly in those exercises designed for a single class period.

\subsection{Define the resources available to the players}

There are many resources that can be used to demonstrate and illustrate a particular concept or process. Economics and finance involve the study of scarce resources, opportunity costs, and the resulting trade-offs that affect decision-making. The more obvious resources include capital, ownership of goods, or authority. Less tangible resources may include influence over other players, high or low status in eyes of other players, or access to the key information needed to make crucial decisions in the game. It is up to us, the designer of the exercise, to decide the resources that players will have available in their various roles. It is also necessary to determine the information that can be provided or will develop within the simulation. If we provide too little information, the players will never be able to develop a solution, but if we give too much information the players will not need to make decisions.

\subsection{Determine the conduct and rules of play}

The substance of a game is the sequence of transactions between the players. It is important at this point to design and formulate a broad or general idea of the sequence of what each player will do during the game. Make sure to check them against the learning objectives. At this point, we are ready to determine what type of transactions will be occurring (e.g., buying, selling, negotiating, planning, scheduling, etc.) and who will interact with whom at each stage. Playing time cycles will also begin to be important considerations at this stage. We must decide whether one or several playing periods are appropriate for the exercise. Exercises that focus on a specific learning objective can usually be completed in a single period, but more complex simulations that require sequential decision making may require weeks to complete. We should also determine the rules at this stage. The rules will state the manner and sequence in which things can be done in the game. They also list the constraints and/ 
or things which cannot be done in the course of the game. It is generally a good idea to simplify the rules as much as possible. One of the biggest pitfalls of beginning game-makers is to design a simulation game that is too complicated. If we have gotten this far, we will have done a lot of research on our game and will know much more about the subject than we can possibly put into a single, simple game or simulation. The challenge is to distill that knowledge down to a simple learning objective that can be achieved through interactive behavior.

\subsection{Formulate the evaluation schema}

The notion of a game implies a win or lose outcome for the participants. In some ways social and business situation do not always produce clear winners or losers. They simply produce results of a process, which can be evaluated as good or bad, valuable, or not. It is very easy to make a simple scoring system or some scheme to figure out who is the winner. But the real value a simulation may be evaluating the value of the outcomes. One possibility is to measure the outcomes in terms of how well a player's personal objectives are met or to what degree the benefit of the players was considered. It is helpful to schedule an evaluation period at the end of any game or at the end of a playing period in which players can get together and talk about what they have learned and what difficulties were encountered. In the use of games, it is critical to use discussion which turns the student's experience into learning.

\subsection{Develop and play the prototype}

It is time to put together the parts of the game into a preliminary playing system. Decide whether to use a simple game, role playing where players interact with each other, or some other setting for the interactions. The actual game materials need to be designed. For example, to represent a probabilistic event we could use dice, a simple spinner, or a deck of playing cards. We could also use a table of random numbers to represent chance events or build a stochastic model using, for example, the random number generating functions in Excel. Review the objectives and scope criteria that were developed in Step 2 to assure that all of the components of the game are aligned with the underlying purpose of the game.

It is best to first play the game with a small group with just enough players to make the exercise feasible. The purpose of a "tryout" of the prototype is to discover if the game plays as we have envisioned. Our job during the tryout is to observe play, record the problems encountered, and devise modifications to improve play. We should not be involved in the play. If the game does not work perfectly the first time, it may take several trials and many modifications before you are satisfied.

\subsection{Refine the prototype}

It is important to understand that there are many things to watch for during the prototype stage: How much time was devoted to each playing period and was it sufficient? Were the rules/instructions easily understood and did they work well? Did the players play the roles easily or with difficulty? At the conclusion of the game, we must ask the students to suggest changes. It is recommended to have a period of evaluation immediately following the game. Some of the questions that should be asked include: How realistic was this game/simulation? How was what we did the same or different from what real decision makers do? What have we learned from this game/simulation? What would happen if the simulation/game had been constructed differently? The evaluation of the game by the players will most likely lead to further suggestions for refinement of the game.

\section{Example of developing a game or simulation}

Words are one thing, and action is something else. This section of the paper presents discussion on the difference between traditional classroom teaching and the use of games and simulations as experiential and active exercises. An example of The Market Game represents a simulation that the authors developed several years ago. The next section illustrates how the previous steps were used to create the Market Game.

\subsection{Identify the problem and the structure of the game}

In general, students do not understand the underlying nature of a free market. Modern commercial activities usually deal with products being offered at fixed prices, and the buyer simply chooses whether or not to pay the price. It must be noticed that there is little or no knowledge of how prices are set in an open, competitive market or how to identify and collect market information. The exercise is structured as a single-period event which includes time for the debriefing session. The "Market game" was developed for students to experience the forces of supply and demand and the determination of an equilibrium price in a variety of market structures. The game was also designed as a simple barter market, the simplest of all market structures. 


\subsection{Define the learning objective and scope}

Students should learn how to gather information concerning the supply and demand characteristics of marketable goods and develop techniques to trade those goods. The specific learning objectives of the game are defined as follows: (a) understand the role of market forces in determining an equilibrium; (b) provide a basis for analyzing the differences in market processes; (c) recognize the value and the role of the information in markets; and (d) recognize the competitive and noncompetitive forces present under different market conditions.

\subsection{Define the players, organizations, and environment}

The class is divided into six trading groups (families) that act both as buyers and sellers. Students are randomly assigned to one of the groups. The players are "trading families" who act both as sellers and buyers in a free market for a variety of items (i.e., animals). For example, there are typically six groups of 3 or 4 students acting as "trading families" in the simple barter version of the game. Each family is assigned an identifying family name that carries no inherent information. We recommend having three to five members in each family. The environment is an area in which the players can move around and interact with each other, usually a classroom.

It should be noted that the number of Traders dictates the complexity of the game. As mentioned earlier, the optimal number of Traders appears to be six. Fewer Traders result in a simplified structure that prohibits some of the more interesting interactions during the game. More than six Traders create a situation where the market becomes so complex that it is impossible for the Traders to grasp what is going on in the market in the relatively short time period of the simulation. Restricting the size of the game to six Traders does not restrict the game to six individuals. It is highly recommended that each Trader be a "family" of three or more individuals. The use of multi-member families creates internal information control problems that add depth to the simulation. If more than twenty-four persons are involved in the simulation, the number of Traders can be doubled by duplicating the original six Traders' market positions. The participants initially will not be aware that two separate trading groups are operating from the same starting position, and once the simulation has begun everything will change. Experience has shown that if only twenty people are involved, it is better to use six Traders and have some families of four members than use twelve Traders and have families with only one member.

During the analysis session following the trading session, it was found that increasing the number of players in a family increases the difficulty of the exchange of information in the market for two reasons. First, students could sample only a small fraction of the market. Second, they faced communication problems which affected their exchange of information among members of their own family and between other families. With smaller groups, communication was more efficient, and it was easier to share information about offers and responses.

\subsection{Define the motives, incentives, and goals of the players}

Each family comes into the market with a list of items they have available to trade and a list of items they need are presented in Table 1 . Table 1 is provided in Appendix A. The players receive no preliminary information concerning market conditions or the supply/demand characteristics of any of the items. The goal of each "trading family" is to maximize its end of game wealth (utility).

\subsection{Define the resources available to the players}

Each "trading family" is given an initial endowment of animals available to trade and also of animals that are needed as presented in Table 1. The students receive no preliminary information on what the experiment is supposed to demonstrate or the market conditions since additional information could influence the actions of the participants. Such information could affect trading behavior and adversely affect the education value of the simulation. At the beginning of the game, a short period is allowed to answer general questions and to review the instructions before trading begins. After the Traders have a chance to make sure they understand the instructions, the simulation is started. When the market opens, Traders start to make deals with other Traders to complete transactions consistent with each Trader's supply of goods and specified needs. When the market opens, the members of each Trading family start to communicate with other Traders to complete transactions consistent with the Trader's instructions. They are free to circulate, gather necessary information, and make transactions at any time. As soon as each transaction is made, it is reported to the family report sheet. Trading continues until the close of the market is announced by the instructor.

\subsection{Determine the Conduct and Rules of Play}

The six trading families engage in barter for the items they "need." The aggregated endowment and 
desires for the various animals define the supply and demand characteristics of the market. Since the goal is wealth (utility) maximization, each family trades to meet their needs. Trading is permitted to continue until exhausted. Each team is given a few minutes to plan how it will approach the market. Different family members may be assigned different actions or roles. The only explicit rule is that players may not use violence in their dealings with other players. When the instructor announces, "the market is open", the players, either as individuals or groups, begin to interact with each other to trade goods. The players make trades with each other until the instructor announces, "the market is closed", and then each team is allowed a few minutes to compile a list of the items that the family currently owns.

\subsection{Formulate the Evaluation Schema}

At the end of the trading session, each trading family reports what "things" it has, including items successfully traded for and items not yet traded away. Determination of the success or failure of each family occurs at two levels. First, families can be identified as winners or losers by determining whether or not they were able to meet their basic needs. Families that meet their "needs" win over those which do not. A second measure of individual family success can be analyzed by considering the final wealth (utility) position as compared to the initial endowment. We must state that this specific scenario will be complicated by the lack of a unit of account!). The success or failure of the market structure could be measured by the ability of all families to meet their basic needs. If the market structure makes it difficult for trades to occur or if the final wealth distribution is unreasonable, the market structure has failed. In this particular way, the "Market Game" could be used to test and demonstrate the effectiveness of alternative market structures as well as provide the students with the opportunity to make and test suggestions to improve the performance of the market. (e.g., transparent market supply/ demand schedules, introduction of money). In the experiments conducted, all transactions tended to move quickly toward the theoretical equilibrium. Almost all transactions were at or very near to the market equilibria by the time the trading period was over. At the end of the experiment, the transactions for each trading family and for the total market were presented so that the Traders were able to observe how their behavior and the structure of the market led to a specific equilibrium.

\subsection{Develop a Prototype and Play}

The first task in the Market Game is to develop a market structure. The instructor must determine what items will be available in the market and the relative supply and demand for each item. An example of a Master Matrix is shown in Table 2 that is included in Appendix B.

At this point, the instructor creates the specific market conditions that will illustrate the learning objective of the exercise. All items could be in shortage, in surplus, or evenly distributed across the market. For this exercise the objective is to learn about market structures, so all market conditions are created. The designer must then determine the distribution of items to the various family groups (Table 1). It is possible to create a "rich" family by giving it items that are in shortage and requiring it to obtain items that are in surplus. A "poor" family would only have surplus items to trade while needing to obtain shortage items. Individual families can even be given monopoly and monopsony positions in the market. Since the purpose of this simulation was to introduce basic market concepts, all families were given similar initial wealth positions.

Conducting the Market Game is reasonably simple since we do not require specialized equipment. An example of the Market Game timeline shows how the game can be run includes: (a) teams with 3-4 members each; (b) distribute an individual trading sheet to each team; (c) give the teams a few minutes to review the items they have available to trade and the items the need. Each team should develop its strategy and assign the various roles the team members will use in the trading session; (d) open the market; (e) allow the players to interact and trade items; (f) close the market; (g) have each team create an inventory of all items currently owned; (h) conduct the debriefing session to discuss items like market behavior, market strategy, price discovery, and information flow. The debriefing session can also be used to focus on those aspects of the market that the instructor wishes to highlight.

The prototype for the Market Game is quite simple. If the prototype for a game becomes complex, it is unlikely that the exercise will be successful. The step from prototype to working model can only become more complex due to the identification of problems with the prototype. It may be that the prototype does play out in a simple mode. If so, we can add bells and whistles to highlight other, maybe new, objectives. But at the prototype stage the guiding rule is keep it simple.

The debriefing session is used to identify the "lessons learned" from the exercise. When a game is played for the first time, the debriefing session becomes a valuable source of information concerning those aspects of the exercise that need to 
be revised, enhanced, or eliminated. The questions and answers that occur during this period not only reveal whether or not the exercise achieved the desired goals but also identifies structural relationships within the simulation. The first debriefing is probably the most important in finding any pieces of the exercise that need improvement, but even after a simulation has been played many times student comments can lead to further refinements and even to entirely new uses for the simulation.

The objective of the Market Game is to teach students about the functioning of markets and the flows of information that can be used to identify market structures. The questions used in the debriefing should address those aspects directly. While the questions may be somewhat general to very specific, they must all deal with the objective of the exercise.

Some of the questions used in debriefing the Market Game are: Did get everything you needed?; What techniques did you use to obtain the needed items?; What was the main obstacle in obtaining items?; What strategy or strategies did you take?; Based on the experience you gained, did you develop a different strategy?; Did you observe any differences in results obtained when you changed your strategies?; How did you gather information you obtained?; What information was needed to accomplish your task successfully?; and What market dynamics did you observe while completing your tasks?

It is important to note that we must complete a census of the items. Ask each team how many of a certain item they own, either because they brought it to the market and did not trade it away or because they traded other items for it. In this particular version of the Market Game, we had 1,000 tigers brought into the market and 1,200 demanded; tigers were a shortage item. When all families report the number of tigers, they own at the end of the trading session, it is unlikely that the number will be 1,000 . The players will either have created or killed some tigers. Some of the items will have a clean count, but in over 100 plays of the game there has only been one time when a student group had a correct count on all items. This situation gives the opportunity to discuss the role of accounting and bookkeeping in business.

A major discussion point concerns communication. As students are trading their various items, deals are being made in multiple locations simultaneously. The difficulty with gathering accurate information concerning the supply/demand characteristics of the market highlights the need for organized communications and business systems. This particular scenario is one of the most important points in the exercise because it gets the players to think about the importance of communications and communications skills in all aspects of life.

\subsection{Refine the Prototype}

The first playing of the game will reveal some aspect of the game that the designer had not anticipated. Even if the game flows smoothly and achieves the desired goal, that goal will be achieved via some unplanned and unforeseen combination of events. The designer must now modify the game to achieve exactly what was wanted or to incorporate the new information which can be one of the most interesting parts of the design process. No matter how much experience a game designer has, there is always something new to learn.

A Market Game that is already robust may develop into a master game with numerous spin offs. Every time a game is played, it is like playing a prototype game. Some games that have a long life and many plays behind them are fairly predictable in their outcomes, but every new set of players takes the game in a slightly different direction. The designer must be attuned to the subtleties of those changes and adapt them to future plays of the game.

The simplest form of market experiment is single-period barter. This form is the first step in developing advanced market structures and is critically important. Other levels of the simulation cannot be conducted effectively until this simulation has been completed. The first playing of the "Market Game" revealed aspects of the game that we had not anticipated. For example, the accounting procedures were not fully developed. As a result, we now provide the players with a specially designed accounting sheet. Also, some traders reneged on trading agreements in order to trade with other traders who subsequently provided them with a better deal. To prevent this "unethical" behavior, we adopted a technique of "shaking hands" which symbolized a contract between the traders.

In fact, the Market Game has undergone extensive modifications and extensions since its prototyping as a result of its use and reuse in the classroom. In fact, each time a game is played, it can be considered a prototype for the next iteration of continuous improvement and refinement. Several modifications to the "Market game" have been implemented which has led to new games such as: Money Game, Inflation Game, Foreign Exchange Game, Monopoly and Monopsony Game, and Oligopoly Game.

Individuals today have been brought up in a market climate that includes prices that might be set by market mechanisms or governmental edict, but they are presented to the buyer. Sometimes buyers engage in rudimentary bargaining, such as in the purchase of an automobile, but this type of bargaining is merely fine tuning around an initial 
given price. In almost all markets, the prices given involve the concept of money. Money and monetary policies are very powerful in and of themselves, but they are not necessary for the functioning of a market. In order to understand markets, it is necessary for Traders to understand that market and monetary structures are separate concepts. The first experiment of single-period barter therefore is useful for all individuals, regardless of their previous market background and experience.

The Market Game is a relatively robust platform due to its lack of rigid structure. A number of refinements and modifications have been made, and several other simulations have been created using the Market Game as a base. When a currency is added, the Money Game teaches price discovery techniques. Inflation can be introduced by expanding the money supply during the game. The addition of a second currency leads to the Foreign Exchange Game which requires establishing currency exchange rates and introduces purchasing power parity concepts. Each time a game is played, it can be considered a prototype for the next iteration of continuous improvement and refinement.

\section{Post-game discussion and debriefing}

The most important part of any game and simulation is reviewing the lessons learned from the play as this is a stage of game where the participants' experiences are transformed into education. Merely "playing a game" in a classroom is not sufficient. We recommend a review that reinforces the exercise's goals. The debriefing can be the most difficult aspect of any game, since it is quite possible that things occurred during the game are not anticipated. The game leader must be aware of everything that is happening during the game, even the unplanned events, and be able to translate all the activity into a set of lessons learned. If there are multiple observers, each can add his or her observations to the debriefing and thus enrich the experience.

The debriefing session is characterized by student participation. The debriefing is the actual goal of any game, getting students involved in and responsible for their own education. It may be useful for the instructor asks questions like: How "real" was the exercise? How did the exercise parallel or different from the real world? What was learned from the exercise? and What would happen if the exercise had been conducted differently?

Students want to tell of their experiences and observations. They can be expected to identify the major characteristics of the simulation or game and the problems that existed within it. Students may also present observations concerning the processes within the simulation that were not anticipated by the instructor. Such situations are why the instructor needs to have a broad background and a thorough understanding of the game's structure to identify how those observations fit into the simulation.

During debriefing sessions, students take theoretical concepts and connect them with the exercise. Theory meets reality, and the lesson can take root. Basic concepts that are practiced and learned while playing the game become more meaningful when the students are able to link them with their own experiences. Practice and experience, as basic elements of games, help students reinforce material learned. As students undertake active, effective, and systematic information gathering, theories no longer become abstract concepts that are memorized.

The success of individual teams should open the discussion, and teams should discuss how they gathered and processed information and how they acted upon that information. The discussion can also focus on the roles of individual members of the team. All participants should be drawn into discussion. It is necessary that all players recognize their roles in the simulation.

The importance of the debriefing session cannot be overstated as it is an opportunity to relate the world of the game to the real world is the payoff of the entire exercise. The shared experience of the exercise forms a touchstone that can be used in other class sessions to illustrate other lessons and give them a personal context for the student.

\section{Evaluation of learning outcomes}

It is important to evaluate the effectiveness of the instruction and learning from the exercise. Assessment must be built into every aspect of the design. The capacity of the learners must be assessed in order to determine if the complexity of the game is appropriate. Prior knowledge must be assessed, and the individual strengths of the learners must be considered in the assessment of the assigned roles. Multiple aspects can be assessed. The most important elements of assessment involve identifying the set of skills and knowledge that was learned through the experience. Without assessing the learning and the process, the effectiveness of the instruction is not realized, and the learning is not appreciated. Recognition of the progress of the learner is critical to the learning process. The resources must also be assessed for adequacy.

Success of a simulation as an instructional strategy is dependent on it containing enough realism, support for the learner, opportunities to reflect through writing and dialogue, and assessment of learning and process. The content, process, and context reality relate to the complexity of the simulation. Through careful design, a game or a simulation can maximize the experiential learning process. To evaluate games and simulations as instructional vehicles requires evaluation of the 
techniques and an examination of their use. The uses described below are not mutually exclusive, and it is possible to design a game or simulation to achieve one or more of them. The most common objectives include several ones which are discussed below,

\subsection{Motivating and increasing students' concentration level}

The use of games and simulations is a device for motivating students and increasing students' concentration level No student learns unless he or she is sufficiently motivated. Those experiential pedagogical techniques provide the means by which students are placed in situations calling for maximum performance. Peer pressure usually requires individual students to carry a fair share of the burden of adequate group performance and offer a relatively easy opportunity to introduce the competitive element into the learning situation. Competition is a useful device for generating motivation. Either as an individual competing against another individual or an individual competing with a team against another team, competition tends to elicit greater intensity of effort and application than is usual in noncompetitive situations. An additional benefit that can result from games and simulations is an increased attention span which students appear capable of sustaining while most students in traditional settings are limited in the amount of time during which they are able to concentrate.

\subsection{Altering students' attitudes}

The effectiveness of games and simulations is a means of altering the attitudes held by students. An attitude is considered to be the expression of an internal value such as like or dislike, good or bad toward an external object or objective. Students frequently do not find learning enjoyable; they employ words like "dull" and "boring" to describe their opinion of the learning situation. The use of them in a classroom alters the attitudes of a majority of students toward the educational objectives. Descriptive words change to indicate pleasure with the classroom, and students frequently demonstrate an eagerness to engage in class work not necessarily related to the games and simulations. Although no hard conclusion can be drawn that being fun or being useful are the same, the inclusion of activities that elicit favorable student reaction seems to be beneficial to the entire classroom atmosphere.

\subsection{Acquiring factual and conceptual knowledge and retaining the knowledge acquired}

The effectiveness of games and simulations is a means of enabling students to acquire factual and conceptual knowledge and to retain the knowledge acquired. Proponents of those active learning techniques contend that these techniques are effective in achieving educational objectives in Bloom's cognitive and affective domains. At the upper end of the taxonomy of cognitive educational objectives, Bloom includes those objectives that illustrate the structure of concepts, theories, principles, and relationships of an educational discipline. The burden of successful performance in a game or simulation is placed upon the students. In a well-designed simulation or game, the students are compelled to develop some recognition of relationships among the elements that are demonstrated by the exercise. The instructor designs the structure of knowledge that is reflected within the simulated system. As the students acquire experience, the instructor can move them through discrete situations to develop their own recognition of the structure of knowledge displayed in the simulation or game. Students usually engage in conversation after the class period in which a simulation has been used. Such activities are likely to affect measurements concerning the retention of knowledge.

\subsection{Improving social skills}

The effectiveness of games and simulation as means of enabling students acquire and to improve social skills and to gain confidence in their ability to employ those skills. Social skills are interpreted as interpersonal situations such as the abilities to bargain, persuade, and collect and categorize information in a manner that facilitates decision making, competition, cooperation, and command. All those skills are essential in a world composed of independent persons and groups. Conventional classroom behavior places the teacher and the student in a one-on-one relationship and fails to capitalize upon the benefits that accrue from peer interactions. Games and simulations place students in the position of performing in situations in which successful outcomes are dependent not only upon one student's actions and choices but also upon the actions and choices of others. Students are compelled to recognize the fact of interdependence. A game or a simulation can develop skills that can be transferred to the real world.

\subsection{Exercising the social skills and knowledge previously acquired}

The use of simulation as a social laboratory to provide for students an opportunity to exercise the social skills and knowledge previously acquired, to utilize them in an artificial environment, and to gain some comprehension for the complexities of selected 
social, economic, and business processes. Games and simulations provide opportunities for students to investigate social processes. The students experience through their own actions and observe reactions of other players in a controlled environment. Payoffs are in terms of satisfaction or dissatisfaction and not permanent results as they would be in the real world. Games and simulations provide the means to create a realistic setting for information and action. Information learned can be used to test principles, theories, and business, economic, or financial relationships. Students can experiment inside scenarios that are relatively simple compared to the real world, perform roles that allow them to acquire or to increase their competence in real-life-related tasks, and experience the pressures, demands, and satisfaction that non-participants have no opportunity to experience.

\section{Results of evaluation of learning outcomes}

During the spring of 2019, the US Coast Guard Academy offered a couple of sections of a macroeconomics principles course with the use of games and simulations. The primary goal of implementing them was to enhance the course effectiveness and develop a learning environment that facilitated interactive learning and communication between students and instructor with the use of the active learning. In order to evaluate student learning and instructor teaching effectiveness via games and simulation the authors conducted a student opinion survey. The data was collected at the end of the semester. Each student was given the same feedback form - questionnaire - in which they had to select one of the several ordered categories.

Students expressed that one of the most important characteristics of simulations and games is that they can be fun. Helping students to have fun in the classroom is a solid approach to learning and has many benefits. An important result is that students will be more motivated. The classroom becomes less anxious and less fearful. The likelihood that the classroom will become more of community sharing power is high. When students open up and share ideas and feelings, they tend to shake off their apathy and become ready to take positive action. Any player can make a mistake without fear of negative repercussions. Because of the motivation and lack of anxiety, the teacher should find the students experimenting more broadly or intensely, which in turn increases the likelihood of depth of discovery. Increased learning may also come about because of the involvement of the other students in the game or simulation.

One of important reasons why students should be playing games and simulations is that they get involved in scenarios that reflect some aspect of reality. The active instruments are developed in order to provide insights into many different aspects of business life. Realistic experiences provided in a classroom environment can give the student the opportunity to face challenges that he or she may meet on the job or in life when after school.

From the students' comments the authors learned that the other benefits include: (a) simulations and games provide students a variety of decision-making situations frequently found in the real environment; they are constructed to give students firsthand experiences' (b) students have the opportunity to use skills previously learned and refine them into marketable skills. New skills are also learned during the simulation. Students have the opportunity to experience real life forces via cooperation while developing problem-solving skills in teams; (c) students with all levels of abilities and skills can work together successfully. The value of teamwork is not overlooked. Students learn the importance of working together and of cooperation; (d) communication skills are refined. Oral communications improve as the individuals learn to give and understand directions, clarify tasks, and share in problem-solving activities; (e) simulations and games are a bridge for the student that links the individual with real-life experiences in the security of a controlled environment; and (f) students can demonstrate their individual abilities in an environment different from the traditional classroom setting. Not all students will have the same degree of readiness, but each student's responsibility can be geared or designed to those specific skills the person already possesses or is ready to acquire. Individual needs and progress can be taken into consideration throughout the simulation.

\section{Conclusion}

The format for developing games and simulations in finance and economics education are discussed in this paper. The model for creating those experiential instruments, presented in this paper, can be integrated into the process of developing efficient tools that would create positive learning outcomes. Any active learning instruments that can be used for improving teaching effectiveness through promotion of active and effective information gathering and organization followed by comprehension, application, analysis, synthesis, and evaluation. All those elements contribute to a learning process where cognitive thinking skills are developed and practiced.

Active learning instruments offer our students real experiences and make concepts learned more meaningful. The exercises presented appear to have a strong impact on the students because role-playing facilitates effective active learning, an acceptance of new concepts, and generate increased student interest, enthusiasm, and motivation. They are also 
potentially excellent teaching tools that offer our students hands-on experience, and with care and practice it is possible to design experiential exercises that are both effective and enjoyable.

Games and Simulations contribute to the learning process, particularly in transferring learning from the conceptual base to its ultimate application. The strong relationship between the degree of perceived realism and the perceived contribution of the business game to learning has been observed in most of simulations discussed. They are developed as real-world simulations, and they have proven excellent vehicles for encouraging deep learning and improving student appreciation of the complexity of business. The use of those experiential learning methods provides students with an alternative to traditional classroom methods. They can also provide an effective learning mechanism due to their student-centered and problem-based nature and through the use of collaborative learning methods.

Students' comments from those experiments show that interactive learning works. All experiments were effectively structured to have groups function successfully and to allow students to become an important element in the process of learning. The students' perception of the experiments was unequivocal. The use of the Market Game contributed to their learning and made their classroom study more real. Well-designed simulations and games can facilitate students' learning of both specific domain knowledge and concepts and cognitive skills like decision-making and problem-solving, but such benefits have a cost. Some of the challenges related to experiential learning include time constraints in the classroom, evaluation of the exercise, and extent of guidance provided to the players in the simulations. The interactive and dynamic environment of a game or simulation in and of itself does not necessarily promote transfer, reflection, or understanding. The instructor is responsible for making the activity a genuine learning experience. Development of successful experiential learning tools requires a commitment to the concept of interactive learning and a real interest in making the process work. Simply adding a game or simulation to a class does not guarantee its usefulness.

A rich body of literature supports the use of experiential learning as a teaching technique and documents examples of successful exercises that have and can be used in the classroom. One of the key aspects of any experiential exercise is that it brings a bit of the real-world into the classroom, and just as the world keeps changing so will the need for new and different games and simulations. The challenge of maintaining relevance is part of the system, and instructors choosing to use those exercises will have ample opportunity to expand and extend established active techniques to meet the needs of their class. The instructor is effectively a part of an ongoing experiential exercise how best to use this dynamic teaching method. Each time an exercise is conducted it expands the knowledge base and can be the basis for further research. More findings are needed to determine if games and simulations prepare students to learn critical problem-solving and decision-making skills. These active learning methods can be important teaching tools, but more research is needed to assess if they promote numerous cognitive benefits in learners, such as motivation for learning, visualization, and experimentation.

In conclusion, this article explores a model for developing and evaluating games and simulations in business and economics education. The paper provides students' feedback on their learning with the use of those experiential learning techniques. The findings of this study show that effective instruction requires students to become active participants by using experiential learning activities. When those activities are used to their greatest potential, they significantly enhance traditional classroom instruction.

\section{References}

[1] Klopfer, E., Osterweil, S., and K. Salen. (2009). Moving Learning Games Forward. Cambridge, MA: The Education Arcade.

[2] McGonigal, J. (2011). Reality is Broken: Why Games Make Us Better and How They Can Change the World. New York, NY: Penguin Press.

[3] Litvin, S., and T. Elangovan. (2000). The Travel Agency Management Game: An Effective Classroom Teaching Tool. Journal of Hospitality and Tourism Education, 12(2): 57-64.

[4] Brozik, D., and A. Zapalska. (1999). Interactive Classroom Economics Learning: The Market Game. Social Studies, November/December: 278-282.

[5] Barlett, R., and P. King. (1990). Teaching economics as a laboratory science. Journal of Economic Education. (Spring): 181-193.

[6] Baker, A., Jensen, P., and D.A. Kolb. (2002). Conversational Learning: An Experiential Approach to knowledge Creation. Westport, CT Quorum Books.

[7] Fry, H., Ketteridge, S., and S. Marshall. (Eds). (2009). A handbook for teaching and learning in higher education: Enhancing academic practice (3rd ed.). New York, USA: Routledge.

[8] Kolb, A., and D. Kolb. (2009). On Becoming a Learner: The Concept of Learning Identity. In BamfordRees et. al. (Eds.), Learning Never Ends: Essays on Adult Learning Inspired by the Life and Work of David O. Justice. Chicago, IL: CAEL Forum and News. 
[9] Kolb, A. Y., and D. Kolb. (2008). Experiential Learning Theory: A Dynamic, Holistic Approach to Management Learning, Education and Development (4268). In Armstrong Handbook of Management Learning, Education and Development; The Sage Publication.

[10] Wurdinger, S., and J. Carlson. (2010). Teaching for experiential learning: Five approaches that work. Lanham, MD: Rowman and Littlefield Education.

[11] Cohen, L., Manion, L. and K. Morrison. (2008). A Guide to Teaching Practice, 5th ed., Routledge, Abingdon.

[12] Johnson, D., and R. Johnson. (2008). Social Interdependence Theory and Cooperative Learning: The Teacher's Role. In R. M. Gillies, A. Ashman and J. Terwel (Eds.), Teacher's Role in Implementing Cooperative Learning in the Classroom (pp. 9-37). New York, U.S.A: Springer.

[13] Brozik, D. and A. Zapalska. (2000). The Restaurant Game. Simulation and Gaming. September, pp. 407-416.

[14] Smith, V. (1992). An Experimental Study of Comparative Market Behavior. Journal of Political Economy, 70 (2): 111-137.

[15] Hester, D. (1991). Instructional simulation of a commercial banking system. Journal of Economic Education, (Spring): 111-143.

[16] Litvin, S. and T. Elangovan. (20013). The Travel Agency Management Game: An Effective Classroom Teaching Tool. Journal of Hospitality and Tourism Education.12(2). 57-64.

[17] DeYoung, R. (1993). Market Experiments: The Laboratory Versus the Classroom. Journal of Economic Education, 24 (Fall): 335-351.

[18] Hoggat, A. (1959). An Experimental Business Game. Behavioral Science, 4 (July): 192-203.

[19] Koster, R. (2004). A Theory of Fun for Game Design (1st ed.). Phoenix, AZ: Paraglyph Press.

[20] Zapalska, A. and D. Brozik. (2001). Learning Market Skills through Simulation. Journal of Private Enterprise, Spring. 56-70.

[21] Kolb, D. (1984). Experiential Learning: Experience as the Source of Learning and Development. Englewood Cliffs, N J: Prentice-Hall.

[22] Wells, D. (1991). Laboratory Experiments for Undergraduate Instruction in Economics. Journal of Economic Education, 22 (Summer): 293-300.

[23] Mohatar, E. (1994). Teaching Modeling on Economics: A Pleasant Surprise. Journal of Economics Education, 25: 335-342.

[24] Maier, M., and D. Keenan. (1994). Cooperative Learning in Economics. Economic Inquiry, (April): 358361
[25] Chamberlin, E. (1995). An experimental Imperfect Market. Journal of Political Economy, 56(2): 95-108

[26] Lewis, L., and C. Williams. (1994). Experiential learning: Past and present. In Jackson, L. and Caffarella, R (eds). (1994). Experiential Learning: A New Approach, no. 62 of the New Directions for Adult and Continuing Education Series. San Francisco: Jossey-Bass.

[27] Lewis, D., and D. Wentworth. (1971). A Guide to Games and Simulations for Teaching Economics. New York: Joint Council on Economic Education.

[28] Barab, S. A., Scott, B., Siyahhan, S., Goldstone, R., Ingram Goble, A., Zuiker, S., and S. Warrant. (2009). Transformational play as a curricular scaffold: Using videogames to support science education. Journal of Science Education and Technology 18, 305-320.

[29] Walker, J. (1987). Experimental Economics in the Classroom. Journal of Economic Education, 18 (Winter): 51-57.

[30] Zapalska, A. and D. Brozik. (2001). Learning Market Skills through Simulation. Journal of Private Enterprise, Spring. 56-70. 
Appendix A. Table 1: Individual Trading Sheets: Market Game

\begin{tabular}{|l|l|l|c|}
\hline \multicolumn{4}{|l|}{ FAMILY: RED } \\
\hline \multicolumn{2}{|l|}{ ITEMS TO TRADE } & \multicolumn{2}{l|}{ ITEMS NEEDED } \\
\hline LION & 80 & TIGER & 360 \\
\hline BEAR & 36 & MONKEY & 300 \\
\hline WOLF & 1,200 & CAMEL & 150 \\
\hline WALRUS & 15 & SEAL & 60 \\
\hline BUFFALO & 180 & HYENA & 1,000 \\
\hline SNAKE & 90 & TURTLE & 1,800 \\
\hline
\end{tabular}

\begin{tabular}{|l|c|l|c|}
\hline \multicolumn{4}{|l|}{ FAMILY: BLUE } \\
\hline ITEMS TO TRADE & \multicolumn{2}{l|}{ ITEMS NEEDED } \\
\hline LION & 60 & TIGER & 360 \\
\hline MONKEY & 80 & BEAR & 24 \\
\hline CAMEL & 250 & WOLF & 1,600 \\
\hline WALRUS & 15 & SEAL & 60 \\
\hline BUFFALO & 180 & HYENA & 1,000 \\
\hline TURTLE & 3,750 & SNAKE & 75 \\
\hline
\end{tabular}

\begin{tabular}{|l|c|l|c|}
\hline \multicolumn{4}{|l|}{ FAMILY: GREEN } \\
\hline ITEMS TO TRADE & \multicolumn{3}{l|}{ ITEMS NEEDED } \\
\hline LION & 60 & TIGER & 480 \\
\hline BEAR & 24 & MONKEY & 300 \\
\hline WOLF & 1,200 & CAMEL & 100 \\
\hline SEAL & 100 & WALRUS & 20 \\
\hline HYENA & 5,000 & BUFFALO & 200 \\
\hline TURTLE & 2,250 & SNAKE & 100 \\
\hline
\end{tabular}

\begin{tabular}{|l|c|l|c|}
\hline \multicolumn{4}{|l|}{ FAMILY: ORANGE } \\
\hline \multicolumn{3}{|l|}{ ITEMS TO TRADE } & \multicolumn{2}{l|}{ ITEMS NEEDED } \\
\hline TIGER & 400 & LION & 90 \\
\hline MONKEY & 80 & BEAR & 24 \\
\hline CAMEL & 150 & WOLF & 1,200 \\
\hline WALRUS & 10 & SEAL & 40 \\
\hline HYENA & 5,000 & BUFFALO & 300 \\
\hline SNAKE & 120 & TURTLE & 1,800 \\
\hline
\end{tabular}

\begin{tabular}{|l|c|l|c|}
\hline \multicolumn{4}{|l|}{ FAMILY: YELLOW } \\
\hline ITEMS TO TRADE & \multicolumn{3}{l|}{ ITEMS NEEDED } \\
\hline TIGER & 300 & LION & 90 \\
\hline MONKEY & 120 & BEAR & 36 \\
\hline WOLF & 1,600 & CAMEL & 250 \\
\hline SEAL & 100 & WALRUS & 30 \\
\hline BUFFALO & 120 & HYENA & 1,500 \\
\hline SNAKE & 90 & TURTLE & 2,400 \\
\hline
\end{tabular}

\begin{tabular}{|l|c|l|c|}
\hline \multicolumn{4}{|l|}{ FAMILY: PURPLE } \\
\hline ITEMS TO TRADE & \multicolumn{3}{l|}{ ITEMS NEEDED } \\
\hline TIGER & 300 & LION & 120 \\
\hline MONKEY & 120 & BEAR & 36 \\
\hline CAMEL & 100 & WOLF & 1,200 \\
\hline WALRUS & 10 & SEAL & 40 \\
\hline BUFFALO & 120 & HYENA & 1,500 \\
\hline TURTLE & 1,500 & SNAKE & 75 \\
\hline
\end{tabular}

Source:_Created by Alina Zapalska

Appendix B. Table 2: Master Matrix

\begin{tabular}{|l|l|l|l|}
\hline ITEM & $\begin{array}{l}\text { QUANTITY } \\
\text { SUPPLIED }\end{array}$ & $\begin{array}{l}\text { QUANTITY } \\
\text { DEMANDED }\end{array}$ & $\begin{array}{l}\text { MARKET } \\
\text { STATUS }\end{array}$ \\
\hline LION & 200 & 300 & SHORTAGE \\
\hline TIGER & 1,000 & 1,200 & SHORTAGE \\
\hline BEAR & 60 & 120 & SHORTAGE \\
\hline MONKEY & 400 & 600 & SHORTAGE \\
\hline CAMEL & 500 & 500 & EVEN \\
\hline WOLF & 4,000 & 4,000 & EVEN \\
\hline SEAL & 200 & 200 & EVEN \\
\hline WALRUS & 50 & 50 & EVEN \\
\hline HYENA & 10,000 & 5,000 & SURPLUS \\
\hline BUFFALO & 600 & 500 & SURPLUS \\
\hline SNAKE & 300 & 250 & SURPLUS \\
\hline TURTLE & 7,500 & 6,000 & SURPLUS \\
\hline
\end{tabular}

